\title{
Contribuições da Educação Física no Ensino Infantil
}

\author{
Maria Rosângela Dias Pinheiro ${ }^{1}$;Lucas Vieira de Lima Silva ${ }^{2}$; Nilmara Serafim Chagas ${ }^{3}$; \\ Janilda dos Santos Barbosa ${ }^{4}$
}

\begin{abstract}
Resumo: O presente estudo trata sobre a contribuição do componente curricular Educação Física de forma sistematizada na primeira etapa da Educação Básica, ou seja, no Ensino Infantil, levantando questionamentos e discussões pertinentes em torno da questão em tela. Tenciona mostrar subsídios da prática pedagógica da Educação Física na Educação Infantil como ferramenta eficaz na formação cidadã das crianças. Nesse sentido, em função das nossas inquietações, surgiu o seguinte problema de pesquisa: Como a Educação Física contribui no Ensino Infantil? Acreditamos que a prática pedagógica da Educação Física no ensino infantil tem um papel fundamental, propiciando vivências e experiências de atividades diversificadas no desenvolvimento da criança, permitindo ajudar de maneira destacada no processo de formação cognitiva, motora, afetiva e social desses educandos. Nesses termos, refletimos sobre a necessidade de se inserir a Educação Física na primeira etapa da Educação Básica ao invés de concebê-la apenas como momentos de práticas de caráter meramente recreativos e despretensiosos de uma educação efetivamente humana e engajada com a realidade na qual os sujeitos estão submetidos.
\end{abstract}

Palavras-Chave: Educação física, Educação Infantil, Currículo

\section{Contributions of Physical Education in Children's Learning}

\begin{abstract}
This study focuses on the contribution of the curricular component of Physical Education systematically in the first stage of basic education, ie in Children's Learning, raising questions and pertinent discussions on the issue at hand. Intends to show benefits of teaching practice of physical education in early childhood education as an effective tool in the civic education of children. In this sense, according to our concerns, the following research problem arose: How physical education contributes in Children's Education? We believe that the teaching practice of physical education in children's education has a key role, providing experiences and experiences of diverse activities in child development, allowing help prominently in the process of training cognitive, motor, affective and social these students. In these terms, we reflect on the need to insert the Physical Education in the first stage of basic education rather than conceive of it only as moments of merely recreational and unpretentious character of practices of a truly human and engaged education with the reality in which subjects they are submitted.
\end{abstract}

Keywords: Physical Education, Children Education, Curriculum

\section{Introdução}

Justificamos a necessidade de realização deste trabalho de pesquisa a partir de duas destacadas inquietações: uma, por percebermos que na primeira etapa da educação básica há uma carência da prática pedagógica da Educação Física no ensino infantil, fragilizando a vivência desse componente

\footnotetext{
${ }^{1}$ Licenciada em Educação Física pela Universidade Regional do Cariri. Especialista em Fisiologia do Exercício E Grupos Especiais pela Faculdade Leão Sampaio em Juazeiro do Norte - Ceará. Especialista em Educação Física Escolar pela Faculdade São Francisco da Paraíba. Docente na Universidade Regional do Cariri e da Faculdade Vale do Salgado, Ceará. E-mail: rosangelapinheiroigt@ hotmail.com;

${ }^{2}$ Doutorado em Educação pela Universidade Federal da Paraíba. Mestre em Sociologia pela Universidade Federal do Ceará. Especialização em Pesquisa em Educação Física, com habilitação em Ciências do Esporte e, Licenciatura Plena pela Universidade Federal da Paraíba. Professor efetivo da Universidade Regional do Cariri. E-mail: vieira11silva@hotmail.com;

${ }^{3}$ Licenciada em Educação Física pela Universidade Regional do Cariri. Especialista em Fisiologia do Exercício e Grupos Especiais pela Faculdade Leão Sampaio, Ceará. Especialista em Educação Física Escolar pela Faculdade São Francisco da Paraíba. Docente da Universidade Regional do Cariri, Campus Iguatu-Ceará e, da Faculdade Vale do Salgado, Icó-Ceará. Email: nschagas@hotmail.com;

${ }^{4}$ Professora no Município de Juazeido do Norte -
} 
curricular nessa fase de ensino; e a outra, pela inexistência de pesquisas na região Centro Sul do Ceará sobre a temática, possibilitando-nos, por meio desta investigação bibliográfica, construirmos referencial teórico específico capaz de subsidiar a materialização de novas pesquisas de campo no contexto do ensino infantil da referida região.

A presente pesquisa é de natureza qualitativa, bibliográfica e de caráter exploratório. Para esse estudo foram realizadas consultas e leituras minuciosas de textos de livros, periódicos e artigos procurados em sites relativos ao tema proposto. Depois deste processo de leitura realizamos fichamentos, a partir dos quais foram elaborados textos que comporam a parte teórica e conceitual desse trabalho.

Dividimos o trabalho em quatro partes. Na primeira apresentamos o referencial teórico do estudo, em que tratamos sobre os conceitos e contextos do campo da educação infantil, como, também, da legislação que rege essa etapa de ensino. Em seguida, realizamos um estudo sobre os diferentes conceitos de educação física, abordando as características e os conteúdos que essa disciplina trata na escola. Após isso, tratamos de discutir como a educação física escolar contribui para o ensino infantil a partir do olhar de diferentes autores que norteiam o estudo proposto. E, por último, debruçamo-nos sobre as considerações finais, destacando nossas impressões e questionamentos sobre o estudo.

\section{Ensino Infantil}

Com a promulgação da Lei de Diretrizes e Bases da Educação N 9.394/96 de 20 de dezembro de 1996 a educação até seis anos ficou definida como primeira etapa da Educação Básica. Mas com a alteração ocorrida em maio de 2005, definiu-se que a criança com seis anos de idade deveria estar matriculada no ensino fundamental. Nesse contexto, a educação infantil passou atender crianças até cinco anos de idade.

A Lei de Diretrizes e Bases em seu Art. 30 reforça que a "educação infantil será oferecida em creches, ou entidades equivalentes, para crianças de até três anos de idade; pré-escolas, para as crianças de quatro a cinco anos de idade" (BRASIL, 1996, p. 21).

A Educação Infantil é a base para o desenvolvimento da criança e seu desempenho posterior em outras etapas da educação. Assim, entendemos que construções e ampliações dos saberes infantil, além de necessários, constituem uma condição importante para o desempenho da criança nos primeiros anos da Educação Básica.

No que se refere à primeira etapa da Educação Básica, recorremos, mais uma vez, a Lei de Diretrizes e Bases da Educação para compreender melhor sua função e organização. Em seu Art. 29, a 
legislação assegura que "a educação infantil, primeira etapa da educação básica, tem como finalidade o desenvolvimento integral da criança até cinco anos de idade, em seus aspectos físicos, psicológicos, intelectual e social [...]" (BRASIL, 1996, p. 21).

É nessa etapa da educação que a criança tem o primeiro contato com a vida escolar, adquirindo conhecimentos, compartilhando experiências e vivenciando um acervo de atividades diversificadas que servirão como bagagem para as séries posteriores.

O Art. 31 da Lei de Diretrizes e Bases da Educação atesta que a educação infantil será instituída por meio das seguintes regras:

[...] I - avaliação mediante acompanhamento e registro do desenvolvimento das crianças, sem o objetivo de promoção, mesmo para o acesso ao ensino fundamental; II - carga horária mínima anual de 800 (oitocentas) horas, distribuída por um mínimo de 200 (duzentos) dias de trabalho educacional; III - atendimento à criança de, no mínimo, 04 (quatro) horas diárias para o turno parcial e de 7 (sete) horas para a jornada integral; IV - controle de frequência pela instituição de educação préescolar, exigida a frequência mínima de $60 \%$ (sessenta por cento) do total de horas; $\mathrm{V}$ - expedição de documentação que permita atestar os processos de desenvolvimento e aprendizagem da criança (BRASIL, 1996, p. 21-22).

É importante mencionar que o objetivo primeiro dessa etapa da Educação Básica é o desenvolvimento integral da criança sem a intenção de submetê-la, precocemente, à promoção de etapas posteriores. Esse desenvolvimento deve acontecer de forma contínua e é identificado através de avaliação sistemática, sucessiva e processual realizada pelo professor através de registros que certifique o desenvolvimento da criança durante essa fase. A instituição escolar tem o papel de controlar a frequência com intuito de verificar a assiduidade dessas crianças, sejam elas atendidas no turno parcial ou durante a jornada integral.

Portanto, durante essa fase da educação básica é oportunizado a criança e ao adolescente os direitos de se desenvolver de maneira plena, integral e cidadã através de inúmeras e diferenciadas vivências e experiências.

Dessa forma, o Estatuto da Criança e do Adolescente (ECA) em seu Art. $3^{\circ}$ afirma que:

[...] a criança e o adolescente gozam de todos os direitos fundamentais inerentes à pessoa humana, sem prejuízo da proteção integral de que trata esta lei, assegurandose lhes, por lei ou por outros meios, todas as oportunidades e facilidades, a fim de lhes facultar o desenvolvimento físico, mental, moral, espiritual e social, em condições de liberdade e de dignidade (BRASIL, 2010, p. 12).

Nesse sentido, falando ainda sobre os aspectos legais que regem a educação infantil, não podemos deixar de citar nesse contexto o Referencial Curricular Nacional para a Educação Infantil (RCNEI). Trata-se de um documento criado em 1998 para servir como um guia de reflexão sobre 
objetivos, conteúdos e orientações didáticas para os profissionais que atuam diretamente com crianças de zero a cinco anos (BRASIL, 1998).

O RCNEI diz respeito a "uma proposta aberta, flexível e não obrigatória, que poderá subsidiar os sistemas educacionais, que assim o desejarem, na elaboração ou implementação de programas e currículos condizentes com suas realidades e singularidades" (BRASIL, 1998, p.14). Este documento apresenta três volumes: 1) Introdução (apresenta uma reflexão sobre creches e pré-escolas no Brasil, situando e fundamentando concepções de criança, de educação, de instituição e do profissional destinado a lidar nesta fase da educação); 2) Formação Pessoal e Social (contém o eixo de trabalho que favorece, prioritariamente, os processos de construção da Identidade e Autonomia das crianças); 3) Conhecimento de Mundo (contém seis documentos referentes aos eixos de trabalho orientados para a construção das diferentes linguagens pelas crianças e para as relações que estabelecem com os objetos de conhecimento: Movimento, Música, Artes Visuais, Linguagem Oral e Escrita, Natureza e Sociedade e Matemática).

O RCNEI (1998, p.21), em seu Volume I nos esclarece que:

\begin{abstract}
A criança como todo ser humano, é um sujeito social e histórico e faz parte de uma organização familiar que está inserida em uma sociedade, com uma determinada cultura, em um determinado momento histórico. É profundamente marcada pelo meio social em que se desenvolve, mas também o marca. A criança tem na família, biológica ou não, um ponto de referência fundamental, apesar da multiplicidade de interações sociais que estabelece com outras instituições sociais.
\end{abstract}

Portanto, a criança por viver em um ambiente familiar e por estar nas relações com as outras pessoas é constituída pelas vivências e experiências, trazendo consigo as marcas indeléveis de várias culturas, valores, códigos, sentidos e significados que a caracterizam como um ser notadamente histórico e social.

Compreendemos a criança como ser histórico, único e indissociável que deve ser estimulada em ambientes propícios às aprendizagens e aos constantes processos de acomodação e assimilação do conhecimento, tendo em vista o constante exercício da construção através da sua interação com o mundo, na resolução dos problemas, num processo de organização e reorganização do conhecimento (FREIRE, 1989).

A criança tem um jeito de sentir e de agir muito próprio, estabelecendo relações precocemente com as pessoas que lhe são mais próximas, revelando seu esforço para compreender o mundo ao seu redor, através de seus desejos e anseios.

Neste item trouxemos discussões a respeito dos documentos que regem a educação infantil. Esses documentos consultados não tratam, na verdade, sobre a Educação Física, mas podemos fazer suposições tendo em vista que há uma orientação para que, no ensino infantil, essa área do conhecimento seja trabalhada/desenvolvida por pedagogos. Essas recomendações parecem desvendar 
uma compreensão equivocada e reducionista por essas proposições, demonstrando, por parte de quem as elabora uma compreensão reducionista de sua importância nessa fase do ensino. Essa situação passa a desencadear problemas basilares. Se por um lado, a disciplina passa a ser lecionada por pedagogos como sinônimo de recreação, por outro, esse mesmo pedagogo, além de não dispor de formação suficiente para tal, passa a ser sobrecarregado nas suas atribuições, não conseguindo dar conta nem da possibilidade de aplicação de uma Educação Física de qualidade e nem tão pouco de garantir com qualidade o seu trabalho mais específico na condição de pedagogo da educação infantil.

Dessa maneira, fica o entendimento e a constatação de que qualquer profissional ou qualquer um sem a devida qualificação leciona Educação Física, principalmente quando se tem a compreensão de que ministrá-la diz respeito a atividades meramente lúdico-motoras as quais só servem para reforçar e legitimar a não necessidade da sua efetiva presença no ensino infantil, negando a relevante presença dessa área do conhecimento nesse âmbito de ensino. O intuito deste trabalho vale lembrar, é o de trazer discussões e reflexões sobre a contribuição da Educação Física no ensino infantil, tornando-se necessário, antes de tudo, fazermos uma breve contextualização sobre a Educação Física enquanto prática pedagógica na escola.

\section{A Educação Física}

A Educação Física como disciplina constitui-se como uma prática pedagógica que através do seu repertório de conteúdos encontra-se inserida no ambiente escolar com objetivo de formar, socializar e desenvolver os alunos em seus aspectos cognitivo, físico, afetivo e social.

Nesse sentido, o Coletivo de Autores (1992, p. 50) nos fala que:

[...] a educação física é uma prática pedagógica que no âmbito escolar, tematiza formas de atividades expressivas corporais como: jogo, esporte, dança, ginástica, formas estas que configuram uma área de conhecimento que podemos chamar de cultura corporal".

A LDB reforça em seu Art. 26, parágrafo $3^{\circ}$, a legalidade da oferta da Educação Física desde as primeiras séries da educação formal, determinando que "A Educação Física, integrada à proposta pedagógica da escola, é componente curricular obrigatório da educação básica (...)” (BRASIL, 2003, p.19).

A LDB deixa claro essa legalidade e a inserção desse componente curricular no âmbito escolar desde as séries iniciais até as posteriores, mas não é o que acontece na prática. Os sistemas de ensino negam esse conhecimento aos alunos da educação infantil e das séries iniciais do ensino fundamental, contemplando-a, somente, no ensino fundamental II ( $6^{\circ}$ ao $9^{\circ}$ ano $)$ e ensino médio.

Betti e Zuliani (2002, p. 75) afirmam que: 
A Educação Física enquanto componente curricular da Educação básica deve assumir então outra tarefa: introduzir e integrar o aluno na cultura corporal de movimento, formando o cidadão que vai produzi-la, reproduzi-la e transformá-la, instrumentalizando-o para usufruir do jogo, do esporte, das atividades rítmicas e dança, das ginásticas e práticas de aptidão física, em benefício da qualidade de vida.

A Educação Física no contexto escolar tem uma singularidade em relação às demais disciplinas. É um componente que contribui para a formação dos alunos através de instrumentos e conhecimentos diferenciados. Esses conhecimentos são apropriados a partir das manifestações de práticas que foram produzidas historicamente pela humanidade em suas relações sociais. Trata-se de uma área que requer espaços e tempos distintos daqueles tratados no ambiente escolar, exige ambiente físico arejado, amplo, protegido do excesso do sol e da chuva, com materiais adequados à sua prática. Esse conhecimento vai além dos muros da escola, interagindo com a comunidade escolar, explorando também outros espaços diferentes do contexto escolar como as ruas, praias, rios, praças públicas, montanhas, cachoeiras, etc. (ORIENTAÇÕES CURRICULARES PARA O ENSINO MÉDIO, 2006).

Portanto, percebemos que a educação física é uma disciplina diferente das demais existentes no âmbito educacional, pois além de possuir um acervo de conhecimentos próprios exige espaços e equipamentos didático-pedagógicos específicos para que ocorra o desenvolvimento satisfatório das aulas da cultura corporal de movimento. Além disso, esses conhecimentos podem ser vivenciados com a comunidade escolar em diversos outros ambientes como ruas, praças, montanhas, rios e tantos outros que poderiam ser aqui mencionados.

Os conteúdos da Educação Física são compostos por uma multiplicidade de práticas corporais concretizadas nos contextos culturais, trazendo consigo valores, sentidos e significados produzidos e reproduzidos no desenvolvimento dessas manifestações corpóreas. Essas práticas são denominadas de manifestações corporais constituídas pelo esporte, ginástica, dança, lutas e jogos e brincadeiras.

Esses saberes são construídos pela humanidade através dos mais diferenciados temas como gênero, práticas corporais em espaços públicos etc. Cada um desses conteúdos possui uma ligação social com a realidade atual como, por exemplo: o esporte à indústria cultural e a produção e venda de produtos através da televisão; a dança possui vinculações étnicas, culturais e históricas, como, também, relações de gênero que podem ser discutidas na escola; a ginástica e as lutas estão vinculadas às influências dos vários povos e culturas. Carregam o simbolismo da beleza corporal, do corpo saudável e do mito da longevidade; e os jogos representam a singularidade e a identificação dos grupos, como os traços da África, da Europa e do índio desde os jogos dançantes até a simulação de combate, de festas religiosas, ritos sagrados de produção como o plantio e a colheita. Os jogos são tradição e consolidação de identidades (ORIENTAÇÕES CURRICULARES PARA O ENSINO MÉDIO, 2006). 
A Educação Física brasileira, durante toda sua trajetória histórica assumiu diversos papéis na escola e na sociedade: eugenização e assepsia do corpo; formação de atletas; preparação do corpo do aluno para o mundo do trabalho; terapia psicomotora e outros papéis do gênero, sobretudo vivenciados ao longo do século XX. Mas contrapondo-se a essas atribuições de cunho idealistas, ela passou, também, a adotar outras posturas político-ideológicas numa perspectiva progressista.

Nessa direção, Betti e Zulliani (2002, p. 74-75) afirmam que a “[...] Educação Física deve assumir a responsabilidade de formar um cidadão capaz de posicionar-se criticamente diante das novas formas da cultura corporal de movimento", passando a construir nos alunos a noção de que não bastam apenas aprenderem as destrezas e habilidades motoras, a apreenderem os fundamentos técnicos e táticos de um esporte, mas precisam, principalmente, aprender a praticar e organizar socialmente suas práticas e saberem respeitar o adversário como companheiro e não vê-lo como inimigo, bem como compreenderem o sentido e significado que as práticas corporais que vivenciam estão diretamente relacionadas ao contexto social, político e econômico do qual fazem parte.

Recorrendo mais uma vez a Betti e Zuliani (2002, p. 75), eles nos revelam que "é tarefa da Educação Física preparar o aluno para ser um praticante lúcido e ativo, que incorpore o esporte e os demais componentes da cultura corporal em sua vida, para deles tirar o melhor proveito possível".

A Educação Física deve levar o sujeito a descobrir motivos e sentidos nas práticas corporais, favorecer o desenvolvimento de suas atitudes positivas, levar à aprendizagem de comportamentos adequados à sua prática, conduzir ao conhecimento, compreensão e análise de seu intelecto, dos dados científicos e filosóficos relacionados à cultura corporal de movimento, apreender a dirigir sua vontade e sua emoção para a prática e a apreciação do corpo em movimento (BETTI, 1992). Esse seria um dos grandes motivos da necessária e efetiva presença da Educação Física no ensino infantil.

Diante do que foi até aqui exposto vale ressaltar a importância da Educação Física como componente curricular obrigatório e seu papel pedagógico no âmbito escolar, constituído de valores, conhecimentos, atitudes e habilidades, devendo proporcionar aos seus alunos o sentido e o significado das práticas da cultura corporal de movimento.

\section{A Contribuição da Educação Física no Ensino Infantil}

A Educação Física representa um papel fundamental na educação infantil, oportunizando a diversidade de vivências e experiências de atividades que irão contribuir para o desenvolvimento cognitivo, motor, afetivo e social da criança, mas, também, despertar o olhar crítico e criativo da mesma sobre si própria e as coisas do mundo. Essas experiências e vivências permitem que a criança valorize seu próprio corpo e descubra as possibilidades de cada movimento desvelando às suas inúmeras capacidades e potencialidades. 
Na Educação Infantil, a Educação Física desempenha um papel importante. Nessa fase da vida, a criança encontra-se em pleno desenvolvimento das funções cognitivas, motoras, emocionais e sociais, passando da fase do individualismo para a das vivências em grupo e, nesse sentido, paradoxalmente, tornando-se cada vez mais indivíduo autônomo em seu agir no mundo e na relação com os outros.

Nesse sentido, a aula de Educação Física representa o espaço favorável para um aprendizado por meio das brincadeiras, desenvolvendo-se os aspectos cognitivo, afetivo-social, motor e emocional conjuntamente (GODOY et al, 2007).

Santana (2008, p. 03) nos esclarece que a Educação Física confere um importante “[...] papel no processo de educação global, não devendo ser vista como algo complementar, mas como uma real contribuição no processo de crescimento e desenvolvimento de todas as pessoas". Dessa maneira, juntamente com as demais disciplinas do currículo da educação infantil, a Educação Física oferece sua significativa contribuição proporcionando às crianças o conhecimento das vivências das manifestações corporais (esportes, jogos, lutas, dança e ginástica) de forma sistematizada e orientada por um profissional habilitado na área o qual possa contribuir de maneira eficaz à formação integral desses sujeitos em processo de formação.

Na Educação Infantil ainda se verifica no Brasil - sobretudo em regiões mais pobres e carentes do interior nordestino - que são poucos os exemplos de aulas de Educação Física que são ministradas por professores habilitados na área, e nem sempre estes profissionais, durante sua formação inicial, dispõem de disciplinas que ressaltam, efetivamente, a faixa etária de 0 a 5 anos.

Mello (2007, p.04) reforça que:

Por isso, ainda encontramos, nas escolas desse nível de ensino, duas situações extremas: aulas denominadas de Educação Física que não têm a sistematização necessária e traz atividades muito parecidas com os esportes; ou brincadeiras na areia e equipamentos do parque, sem nenhuma diretividade em nenhum momento.

É imprescindível que haja discussões sobre o papel do professor polivalente e do professor de Educação Física, como, também, em torno das metodologias e conteúdos que são aplicados durante as aulas de Educação Física no Ensino Infantil.

A escola deve fazer uma relação dos conteúdos da Educação Física para o Ensino Infantil. Essa organização e seleção de conteúdos têm o objetivo de promover a leitura da realidade, o conhecimento da cultura corporal de movimento, com o propósito de haver a apreensão da expressão corporal como linguagem, bem como da compreensão da importância de ensino de Educação Física nas escolas infantis (VIEIRA, 2007).

Como vimos no decorrer das breves considerações aqui ventiladas, os professores que atuam no Ensino Infantil, em sua maioria, são profissionais sem uma formação adequada e, em grande parte não estão aptos - ou totalmente prontos - para ministrar a disciplina Educação Física de maneira

33 Id en line Revista de Psicologia. Ano 9, No. 27. Julho/2015 - ISSN 1981-1179. Edição eletrônica em http://idonline.emnuvens.com.br/id 
satisfatória nessa etapa da educação básica, secundarizando e negligenciando os conteúdos, sobretudo por não possuírem os conhecimentos suficientemente adequados e específicos da área.

Por outro lado, no nosso entendimento, a Educação Física deve estar presente na educação infantil plenamente para que os profissionais da área possam aplicar os conteúdos da cultura corporal de movimento através de atividades lúdicas e prazerosas com o propósito maior de contribuir para o desenvolvimento, aprendizagem e crescimento da criança, ressaltando não o movimento pelo movimento, mas o movimento orientado, almejando alcançar objetivos efetivos no sentido de trabalhar os limites e dificuldades das crianças em busca da construção do sujeito cidadão dotado de criatividade e criticidade sobre si, os outros e o mundo do qual faz parte.

Esse é o momento propício para os professores de Educação Física, conscientes da importância do seu papel no processo educacional, reivindicarem pelo direito do seu espaço na educação infantil, para realização de pesquisas que instiguem discussões e uma reflexão mais profícua e profunda sobre o papel do professor de educação e, portanto, Educação Física, e sua valiosa contribuição para o desenvolvimento da criança (ROCHA, 2010), como ser capaz de exercer inteiramente sua cidadania.

Portanto, a escola como local destinado à educação deve propiciar durante as aulas de Educação Física, um saber fazer das práticas corporais e um saber sobre esse fazer, ou seja, sobrepujar a prática pela prática e conscientizar-se que não existe prática neutra, pois nela estão implícitas ou explícitas filosofias, valores, interesses e visões de mundo (GALLARDO, 2005). E não há como construir um olhar aguçado e crítico sobre isso se não se propiciar as condições objetivas e materiais para a formação do sujeito capaz de perceber sua realidade no sentido de ajudar a transformá-la para melhor e em benefícios de todos.

A escola é o local apropriado pela divulgação e construção do conhecimento, propiciando o processo ensino-aprendizagem e que, durante as aulas, o professor possa criar situação para que o aluno, de forma prazerosa, possa assimilar esse conhecimento, ampliando atitudes e habilidades que possibilitem a criticidade e o desenvolvimento de suas capacidades cognoscitivas (ROCHA, 2009).

De acordo com Basei (2008, p.01) a Educação Física:

Tem um papel fundamental na Educação Infantil, pela possibilidade de proporcionar às crianças uma diversidade de experiências através de situações nas quais elas possam criar, inventar, descobrir movimentos novos, reelaborar conceitos e ideias sobre o movimento e suas ações. Além disso, é um espaço para que, através de situações de experiências - com o corpo, com materiais e de interação social - as crianças descubram os próprios limites, enfrentem desafios, conheçam e valorizem o próprio corpo, relacionem-se com outras pessoas, percebam a origem do movimento, expressem sentimentos, utilizando a linguagem corporal, localizem-se no espaço, entre outras situações voltadas ao desenvolvimento de suas capacidades intelectuais e afetivas, numa atuação consciente e crítica. 
Diante do exposto anterior fica evidente a importância e a contribuição da Educação Física no Ensino Infantil, pois trabalha a linguagem corporal, o movimento e a cultura da criança através das manifestações corporais que podem vivenciar.

Então a Educação Física é uma disciplina que pode contribuir para o desenvolvimento integral/total da criança através de atividades lúdicas e prazerosas, principalmente quando da oferta de práticas/atividades bem orientadas e sistematizadas por um professor devidamente habilitado/qualificado na área para atuar profissionalmente na educação infantil, proporcionando à criança a interação com objetos, com outras crianças e com situações que possam servir de aprendizado para sua vida em sociedade. Portanto, a Educação Física enquanto componente curricular pode e deve contribuir de forma consistente e satisfatória com a educação da criança no âmbito da Educação Infantil.

\section{Considerações Finais}

O propósito desse artigo foi o de discorrer sobre a contribuição da prática pedagógica intencional e formadora da Educação Física no Ensino Infantil, vindo a somar, decisivamente, na realidade da práxis educativa na primeira etapa da Educação Básica.

Nos processos aqui elucidados de forma explícita, ou até mesmo nas entrelinhas destes breves e embrionários escritos, quisemos evidenciar a contribuição da Educação Física na primeira etapa da Educação Básica (Ensino Infantil), bem como levantarmos discussões sobre a inserção do professor habilitado na área para tratar dos conhecimentos pertinentes ao acervo das práticas corporais e das manifestações culturais advindas de um processo de construção da própria humanidade, não deixando a Educação Física, na perspectiva da cultura corporal de movimento, se extinguir ou ser desenvolvida por pessoas muitas das vezes forçadas a fazerem coisas que não pretendem e nem se sentem habilitadas para isso.

Em meio a tantas transformações e evoluções que permeiam a educação nacional, acreditamos que se torna necessário conceber esta prática como espaço real de atuação do professor de Educação Física, de fundamentação teórico-prática e instrumentalizadora da atividade profissional no contexto da práxis social, abrindo possibilidades reais de condições de ensino, pesquisa e extensão através de uma prática crítico-reflexiva a partir do contexto do presente objeto de estudo que se preocupa em investigar sobre a contribuição da Educação Física no ensino infantil.

Todas as justificativas e objetivos levantados nesta produção teve realmente como intuito trazer discussões que tratam sobre a importância e a necessidade da Educação Física no ensino infantil e zelar pela formação integral/total e cidadã da criança que se encontra em fase de desenvolvimento (pleno).

35 Id en line Revista de Psicologia. Ano 9, №. 27. Julho/2015 - ISSN 1981-1179. Edição eletrônica em http://idonline.emnuvens.com.br/id 
Ficou-nos evidente nesse estudo a contribuição desse componente curricular no ensino infantil, trazendo à tona o acervo de conhecimentos que são tratados por essa disciplina no âmbito educacional que servirão como aprendizado para uma formação sólida, consistente e eficaz das crianças nessa etapa da educação e fase da vida. A grande relevância dessa área do conhecimento insere-se na possibilidade que ela propicia às crianças ao desenvolvimento de suas corporeidades, sentindo-se e percebendo-se no mundo no sentir, agir e se movimentar nesse mesmo mundo.

Em função do que temos aqui apresentado, acreditamos que a Educação Física se constitui uma matéria de extrema importância no ensino infantil, sobretudo por ser capaz de propor, por meio da cultura corporal de movimento, conteúdos relevantes para a formação de sujeitos mais conscientes e críticos de seu papel como cidadãos, tornando-os aptos a interpretarem sua realidade, instigando-os, ainda, a intervirem de maneira lúcida no meio social na perspectiva de transformá-lo para melhor ao bem de todos e, principalmente, da coletividade.

\section{Referências}

BASEI, Andréia Paula. A Educação Física na Educação Infantil: a importância do movimenta-se e suas contribuições no desenvolvimento da criança. Revista Iberoamericana de Educação. Nº $^{\circ}$ 47/3 de 25 de Outubro de 2008.

BETTI, M. Ensino de $1^{\circ}$. E $2^{\circ}$. Graus: Educação Física para quê? Revista Brasileira de Ciências do Esporte, v. 13, n. 2, p. 282-7, 1992.

BETTI, M; ZULIANI, Luiz Roberto. Educação Física Escolar: uma proposta de diretrizes pedagógicas. Revista Mackenzie de Educação Física e Esporte - Ano 01, Número 1, 2002.

BRASIL. Ministério da Educação. Estatuto da Criança e do Adolescente. Lei $n^{\circ}$ 8.069, de 13 de julho de 1990 e legislação correlata. $7^{\text {a }}$ ed. - Brasília: Câmara dos Deputados, Edições Câmara, 2010.

Ministério da Educação. Lei de Diretrizes e Bases da Educação Nacional. Lei Nº 9.394 de 20 de dezembro de 1996. Brasília: Gráfica do Senado.

Ministério da Educação. Lei de Diretrizes e Bases da Educação Nacional. Lei de $\mathrm{N}^{\circ}$. $10.793,1^{\circ}$ de dezembro de 2003. Altera a redação do art. 26, $\S 3^{\circ}$ e do art. 92 da lei 9.394 , de 20 de dezembro de 1996, que estabelece as diretrizes e bases da educação nacional e da outras providências. Brasília, dezembro, 2003.

Ministério da Educação. Orientações Curriculares para o Ensino Médio: Linguagens, Códigos e suas Tecnologias. Brasília, DF. Secretaria de Educação Básica, 2006.

Ministério da Educação e do Desporto Secretaria de Educação Fundamental. Referencial Curricular Nacional para a Educação Infantil. Brasília: MEC/SEF, 1998.

COLETIVO DE AUTORES. Metodologia do Ensino de Educação Física. São Paulo: Cortez, 1992.

FREIRE, João Batista. Educação de Corpo Inteiro. São Paulo: Scipione, 1989. 
GALLARDO, J.S.P. (org.) Educação Física Escolar: do berçário ao ensino médio. $2^{\mathrm{a}}$ ed. - Rio de Janeiro: Lucerna, 2005.

GODOY, R.P.; KOBAL, M.C.; MAGALHÃES, J.S.; FURTONI, V.M.C. A Educação Física nas Escolas Municipais de Educação Infantil de Jaguariúna/SP. In: Simpósio Regional de Educação Física da FAEFI- PUC Campinas: Educação Física Escolar. Exercício e saúde e Esporte de Aventura. Campinas. Junho, 2007.

MELLO, M.A. Educação Infantil e Educação Física: um binômio separado pelo movimento, mas qual o movimento? Artigo da biblioteca digital da Universidade Federal de São Carlos, 2007.

ROCHA, M. P. Educação Física na Educação Infantil Experiência do Estágio Supervisionado I na Educação Infantil em 2010.1. Disponível em: < <http://congressos.cbce.org.br/index. php/conece/3conece/paper/viewFile/2463/986>. Acesso em: 30 de Novembro de 2014.

ROCHA, Y.F.O. Piaget na Sala de Aula: uma abordagem lúdica. Faculdade de Ensino Superior do Piauí - FAESPI. Publicado em 07 de março de 2009. Disponível em: <http://www.webartigos.com/articles/15237/1/piaget-na-sala-de-aula-uma-abordagemludica/ pagina1.html >. Acesso em: 30 de Novembro de 2014.

SANTANA, J.O. A Educação Física inserida na Educação Infantil: uma análise da realidade da disciplina nas escolas públicas infantis da cidade de Viçosa-MG. Revista Digital - Buenos Aires Ano 13 - $\mathrm{N}^{\circ} 120$ - Maio de 2008. Disponível em: <http://www.efdeportes.com/efd120/a-educacaofisica-inserida-na-educacao-infantil.htm>. Acesso em: 30 de Novembro de 2014.

VIEIRA, M.S. Por uma Educação Física com Sabor: possibilidades e desafios no ensino infantil. In: Anais do XV Congresso Brasileiro de Ciências do Esporte e II Congresso Internacional de Ciências do Esporte. Recife: CBCE, 2007.

\section{Como citar este artigo (Formato ABNT):}

PINHEIRO, M.R.D.P.; SILVA, L.V.L.; CHAGAS, N.S.; BARBOSA, J.S. Contribuições da Educação Física no Ensino Infantil. Id on Line Revista de Psicologia, Julho de 2015, vol.9, n.27. p. 26-37. ISSN 1981-1189.

Recebido: 11/04/2015

Aceito: 23/04/2015 